\title{
WEEE Resource Management System in Costa Rica
}

\author{
Lilliana Abarca-Guerrero ${ }^{1,2, *}$ (1) , Floria Roa-Gutiérrez ${ }^{1}$ (1) and Victoria Rudín-Vega ${ }^{3}$ \\ 1 Chemistry School, Instituto Tecnológico de Costa Rica, Cartago 30101, Costa Rica; froa@itcr.ac.cr \\ 2 Department of the Built Environment, Eindhoven University of Technology, Den Dolech, \\ 25612 AZ Eindhoven, The Netherlands \\ 3 ACEPESA (Asociación Centroamericana para la Economía, la Salud y el Ambiente), San José 40602, \\ Costa Rica; vrudin08@gmail.com \\ * Correspondence: labarca@itcr.ac.cr; Tel.: +506-8832-5488
}

Received: 10 October 2017; Accepted: 19 December 2017; Published: 8 January 2017

\begin{abstract}
Costa Rica followed different steps in order to organise and implement a waste of electrical and electronic equipment (WEEE) management system. This paper summarises the challenges, successes, and limitations of its implementation. Two phases were needed to set up the system. The first phase created a baseline followed by the designing of a strategy. The second phase promoted a Decree for WEEE management that prohibits discarding WEEE together with household waste, as well as the creation of a National Executive Committee with representatives of importers, consumers, and government, which will establish the quotes and treatment fees, and so on. Another outcome was the development of a strategy for the implementation of WEEE management for the country, the promotion of population awareness about their responsibility for WEEE management, and an example set up for other Latin American countries. This paper draws conclusions from the regulation and notes the required consistency with the existing national waste legislation in order to reduce approval times. Additionally, the importance of the participation of stakeholders representing different electric and electronic equipment (EEE) sectors with the purpose of obtaining consensus on agreements is highlighted.
\end{abstract}

Keywords: E-waste; WEEE; systematisation; Extended Producer Responsibility; Costa Rica

\section{Introduction}

The electronic industry is the largest and fastest-growing manufacturing industry. Meanwhile, the amount of waste of electrical and electronic equipment (WEEE) is growing at an alarming rate, and countries in Latin America are no exception, in some cases being similar to industrialised countries [1-3].

The rapid growth of WEEE, lack of prevention and minimisation strategies, indiscriminate dumping and improper disposal, low awareness in society about the environmental hazards and the wide variety of materials they often contain, including many substances potentially harmful to both humans and the environment, has resulted increased attention focussed on how WEEE is generated, and handled, as well as ways in which the production of waste can be prevented [2,4,5]. This situation gave rise to several countries in high-income regions engaging in WEEE policy formulation under principles such as Extended Producer Responsibility (EPR), whereby WEEE manufacturers are assigned the responsibility for environmental impacts throughout the lifecycle of products, including recycling, reuse, and final disposal of waste materials [2]. Simultaneously, this approach was also introduced in some Latin American countries including Costa Rica [3], which has attempted to overcome this rising problem by developing its own method of WEEE management based on the initiative of the Netherlands [6]. 
This article analyses the different steps followed in Costa Rica in order to develop a WEEE management system based on EPR principles. The term Producer has been extended to the importers of new and used equipment since there is no production of electrical or electronic equipment in the country. On the other hand, WEEE refers to all electrical and electronic equipment, but this initiative was limited to information and communication equipment (ICT) due to their shorter life span and the growth of the market and number of users. Therefore, large household appliances and entertainment equipment were not included in the first approach, although in a later stage of this initiative TVs and flat screens were included due to their technological similarity to computer monitors.

\section{Waste of Electrical and Electronic Equipment in Costa Rica}

Costa Rica is a small country in Central America with a surface of $51,100 \mathrm{~km}^{2}$ and a population of approximately 4.9 million inhabitants, of which $60 \%$ is urban. In the urban areas, $45 \%$ have finished primary education, $30 \%$ secondary education, and $14 \%$ university studies. In the rural areas, $64 \%$ have finished primary school and $16 \%$ secondary education [6]. Costa Rica is considered to have a middle-income economy, with a Gross Domestic Product per person of 14,914 US\$-15,401 US\$ in 2015 and 2016 respectively. The country has experienced an increase in the amount of waste due to urbanisation, a rise in population, and changes in consumption patterns. A study in four municipalities of the Great Metropolitan Area showed a generation rate of $0.59 \mathrm{~kg} /$ inhabitants-day [7].

In 2003, Costa Rica developed a very important initiative to determine inventories in different materials. The report alerted organisations and institutions to the need of a sustainable management strategy for WEEE. During this study, it was acknowledged that by 2005, 130,000 personal computers (PCs) would be discarded, representing about 2600 tons. The report also warned about the lack of facilities that provide any treatment and safe final disposal for this type of waste [5]. By 2006, a second inventory reported 11,737 tons of WEEE, which shows the magnification of the WEEE generation due to a higher accessibility to computers as well as other information and telecommunication technologies [8].

The process to start developing a WEEE management system started with three organisations: a national non-governmental organisation (NGO) called the Central American Association for the Economy, Health, and the Environment (ACEPESA), supported by a state university, Instituto Tecnologico de Costa Rica (ITCR); the Chamber of Industries of Costa Rica (CICR); and an International NGO called WASTE, Advisers on Urban Environment and Development from the Netherlands.

The methodological approach used to develop the EPR system was based on the Integrated Sustainable Waste Management Model (ISWM) (see Figure 1), which considers the stakeholders, the material flow, and other issues grouped around technical, financial-economic, socio-cultural, environmental, institutional, and political/legal aspects that influence the full sustainability of waste management [9].

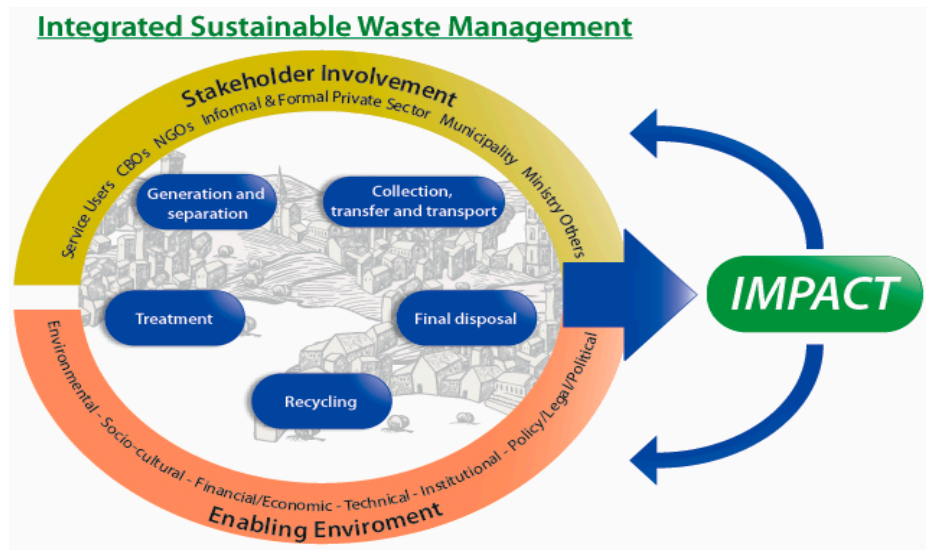

Figure 1. The Integrated Sustainable Waste Management Model [9-11]. 


\section{Methodology}

The project was developed in two phases (see Figure 2) from 2003 to 2007. The first phase, planned for one year, had two objectives: (1) To analyse the current situation in Costa Rica in relation to WEEE management; and (2) To develop a national strategy for WEEE management.

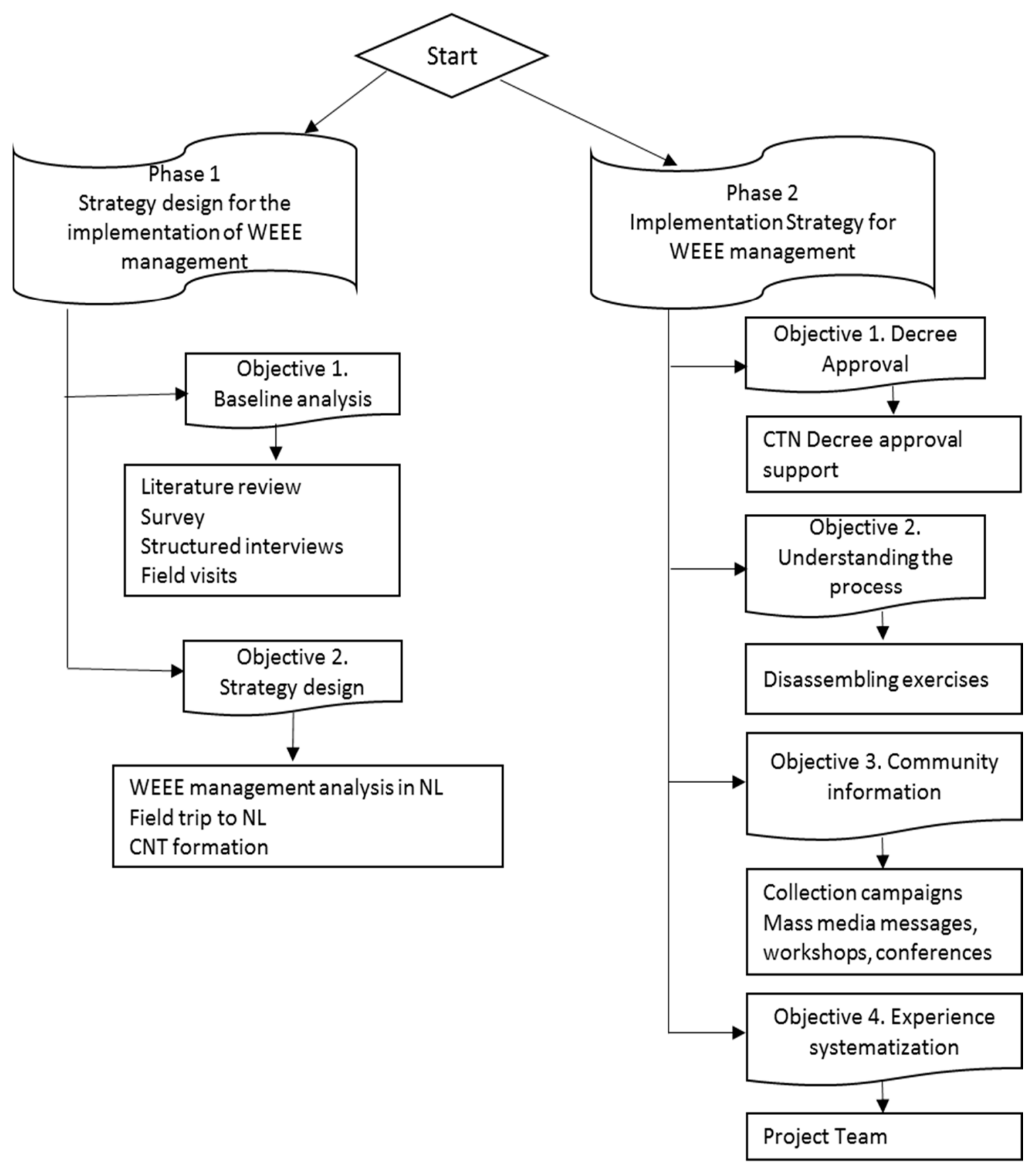

Figure 2. Project phases and methodology used [5].

An inter-sector working team (Executive team) lead the process by starting with the identification of the main stakeholders around electric and electronic equipment (EEE) as well as gathering the information available for the estimation of WEEE generation, identification of main generators, informal dismantling activities and material recovery, and material flows between the stakeholders. The idea was to be able to describe a WEEE system by identifying the stakeholders and to determine 
their present roles and possible environmental and social-economic impacts, building up relevant information for the development of a national strategy for WEEE management.

The second phase, planned for three years, was focused on three objectives: (1) To prepare and discuss the regulation proposal for the WEEE management with government, public, and private sectors in order to achieve its approval by presidential decree; (2) To assess technical and financial feasibility for the WEEE process proposed in the management strategy considering strengths and limitations in the country; and (3) To transfer information about WEEE in order to raise awareness in all sectors of Costa Rican community. The Executive team considered that in order to prepare the National Regulation proposal for WEEE management, an open discussion with all stakeholders, central and local governments, and community members was required. From the first phase results, a lack of formal businesses dedicated to suitable WEEE processing in Costa Rica was encountered, therefore actions to promote WEEE recycling companies were taken towards the implementation of a WEEE management system based on the EPR, followed by information transfer and awareness on WEEE impacts, citizen responsibilities, and technical support for WEEE storage and collection strategies [6].

The executive team included four partner organisations: (1) ACEPESA, as the leader of the initiative; (2) ITCR, which supported the initiative with scientific, technical, and environmental aspects; (3) CICR, as a potential organisation that included not only EEE users and WEEE generators but also producers or industries which could later be involved in WEEE treatment or WEEE material recycling; and (4) WASTE in the Netherlands. In order to generate empowerment of all sectors involved, other organisations joined during the development of this phase, including the Ministry of the Environment and Energy (MINAE), Ministry of Health, the Costa Rica Institute of Electricity and Telecommunications (ICE), and the American Chamber of Commerce (AmCham) represented by Intel and RICOH.

A summary of both phases is found in Figure 2. It contains the two phases as well as the objectives and methodologies used in each phase.

\subsection{First Phase}

The baseline analysis started with a literature review. It provided information on stakeholders involved in WEEE management as well as the findings of similar studies in other parts of the world. Five survey instruments were created to determine the actual situation related to WEEE management in Costa Rica, considering financial, institutional, environmental, technical, socio-cultural, legal, and gender aspects. Two examples can be found in Appendix A. The instruments were oriented to obtain information from the following categories:

(1) Equipment importers and distributors. Importers and distributors existing in the Great Metropolitan Area (GMA) providing services since 2003 independently of its size;

(2) Electric and electronic refurbishing workshops. Workshops in the GMA with services since 2003;

(3) Governmental and private clients. Public and private banks in the GMA, public and private universities with Informatics or Electronic careers, ministries and autonomous institutions, and enterprises that are members of the Industry and Commerce Chambers;

(4) Municipalities. Municipalities from GMA that have that have the responsibility of managing the disposal sites; and

(5) Households. Owners of a desk telephone line in the capital city in 2003.

An estimation of the sample size was made based on a finite population in each category, except for the municipalities and the universities, considering aleatory number techniques with $95 \%$ confidence. The sample sizes are presented in Table 1.

Two hundred and seventy-seven questionnaires were sent to different categories involved with EEE. This amount is lower than the proposed number (342) due to a lower number of existing enterprises in the moment of the study. Additionally, the household survey was conducted to one 
hundred households referring to their habits and behaviours related to WEEE management in addition to their willingness to pay for its safe treatment and disposal.

Thirty-five structured interviews were implemented to key informants from different organisations such as regulatory boards, collection, transportation, final disposal, and recycling entities. Three tools were prepared for the interviews. An example can be found in Appendix B. The interviews were intended to complement the survey in order to process the results obtained from the questionnaires.

Table 1. Total population and sample size.

\begin{tabular}{lclc}
\hline \multicolumn{1}{c}{ Population } & Total & \multicolumn{1}{c}{ Sample Framework } & Sample Size \\
\hline $\begin{array}{l}\text { Equipment importers } \\
\text { and distributors }\end{array}$ & 704 & $\begin{array}{l}\text { Telephone book, 2003 } \\
\text { Commercial Directory, 2003 } \\
\text { Industrial Directory, 2003 } \\
\text { Database of Ministry of Economic, } \\
\text { Industrial, and Commercial Affairs, } \\
\text { December 2002 }\end{array}$ & 85 \\
\hline $\begin{array}{l}\text { Electric and electronic } \\
\text { refurbishing workshops }\end{array}$ & 23 & Telephone book, 2003 & 17 \\
\hline Governmental and & 1.429 & $\begin{array}{l}\text { Commercial Directory, 2003 } \\
\text { Industrial Directory, 2003 } \\
\text { Telephone book, 2003 } \\
\text { Internet }\end{array}$ & 131 \\
\hline Municipalities clients & & $\begin{array}{l}\text { San José, Atenas, Alajuela, Santo } \\
\text { Domingo, Curridabat, Tres Ríos, } \\
\text { San Pablo de Heredia, San Isidro de }\end{array}$ & 100 \\
\hline Households & 9 & Heredia, and Goicoechea. & \\
\hline Total & - & Telephone book 2003 \\
\hline
\end{tabular}

Field visits were conducted after receiving the questionnaire responses and the data collected in the interviews. Observations on processes related to WEEE management were made to material recycling facilities and disposal sites.

The limitations of this phase are related to the collection of quantitative data about the amount of electric and electronic equipment in public and private institutions and the waste generated.

By 2004, the Netherlands WEEE management system was financially and technically well-established. A field trip to the Netherlands coordinated by WASTE allowed the executive team together with government and industry officers to better understand milestones of a Management System based on EPR. The objective was to analyse the WEEE management in the Netherlands (NL), as well as its organisation, challenges, and opportunities in order to adopt a similar system in Costa Rica. A National Technical Committee (CTN from its Spanish acronym) was created after the field trip to the NL. The CTN aimed to plan, monitor, follow-up, and evaluate the project phases. The consolidation of the CTN is considered one of success factors for the establishment of the product of first phase: the National Strategy for integrated WEEE management system by the end of 2005.

\subsection{Second Phase}

The CTN was strengthened after the field visit to NL. They had the task of lobbying the approval of the regulation. Additionally, a program to support the EEE sector in understanding the Decree and its impact was prepared. The regulation proposed promoted the idea of compliance entities that would facilitate the collection, transportation, and treatment of EEE. Simultaneously, trainings were provided to staff members of governmental institutions in the new system.

Regarding the assessment of the technical and financial feasibility (Objective 2) two pilot dismantling exercises were set up to determine collection procedures, storage and transportation needs, 
disassembling and separation requirements, local and international material markets, hazardous EEE material export procedures, final treatment, and international logistics.

The first pilot exercise considered the treatment of an equivalent to 1000 central processing units (CPU), monitors, keyboards, and mouse) provided by the Costa Rica Institute of Technology. The basic requirements for labour, working areas, storage sites, required tools, safety equipment, packaging materials, and dismantling times, among others, were studied. It is noteworthy to mention that the staff for the dismantling procedure consisted of four employees from an industrial waste facility; the four employees were men between 20 and 35 years old, with no previous experience in WEEE dismantling, and a level of education from 9th grade to 11th grade (high school completed). ITCR offered a short training program $(6 \mathrm{~h})$ to staff, including transportation and forklift truck operators, and the program included occupational safety related to WEEE handling, identification of parts, and dismantling procedures.

The second exercise considered all of the phases starting on the storage of the materials, dismantling process, packaging of the different materials, and local commercialisation of the recycling materials, as well as international commercialisation only for those materials that could not be recycled locally. The cost for the treatment was estimated.

Collection campaigns were introduced during the dismantling exercises, leading to a well-informed community eager to participate intensively during the WEEE collection activities. The community received information through different mass media, workshops, and conferences about the environmental and health impact of WEEE, preventive actions, roles and responsibilities of the different stakeholders, the results expected from the project, and the system that was defined through a voluntarily EPR strategy.

\section{Results and Discussion}

During the first phase, the primary and secondary stakeholders involved in WEEE management (see Figure 3) were contacted. They included municipalities, users of EEE, importers and distributors of EEE, repair shops, material recovery facilities, waste processing companies, ministries of Environment, Health, Science, and Technology, academic institutions, union groups, and non-governmental organisations. In addition, this step allowed identifying the institutions and organisations that could contribute as members of the National Technical Committee.

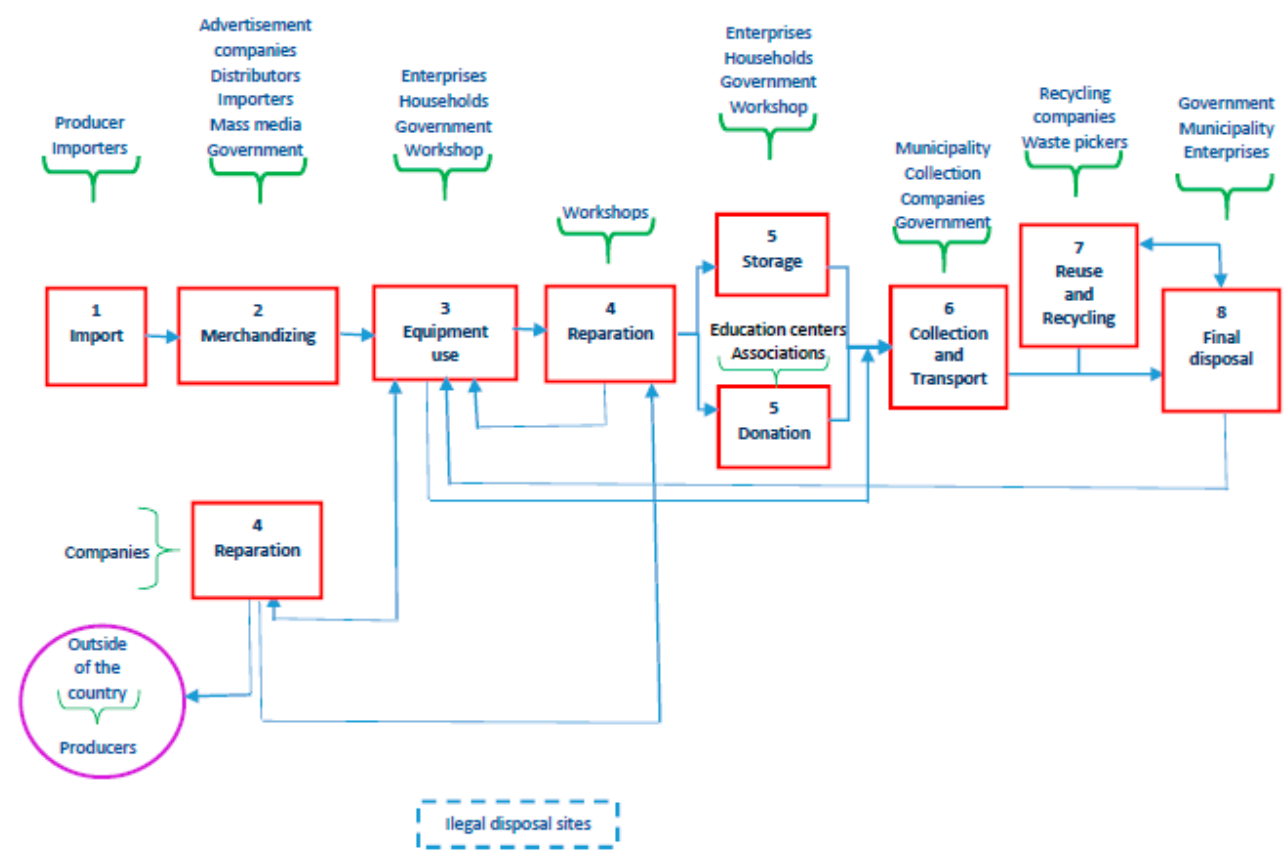

Figure 3. Stakeholders and WEEE management in Costa Rica [5]. 
Furthermore, the study showed that close to 24,000 tons of historical WEEE had been generated since 1996 (first data available) [12]. This amount increased approximately by 4000 tons per year. Although WEEE had started to be dumped in empty lots or river basins, most of it was stored in warehouses in institutions, or closets and garages in the case of individual consumers.

The baseline was set up and the dimension of the problem was better understood; awareness of different sectors about the need to seek options for an environmentally sound system was provided; and the mass media was motivated to actively support the initiative. The strategy design process gave as a result a consolidated and motivated National Technical Committee actively involved as a technical body assuming research, lobbying, and advocacy responsibilities.

The analysis of WEEE management in NL and the field visit to that country provided in-depth information about institutional issues related to WEEE management and the compliance financing system. A national strategy for integrated and sustainable electronic waste management in Costa Rica was formulated and presented to the national authorities, business people in the sector, and households.

During the second phase of the study, the CTN worked on a Decree for WEEE management since the country did not have specific regulation for this type of waste. It was based on the Waste Management Law and the Extended Producer Responsibility principle. The Decree was publicly consulted and approved in May 2010. It was the first one of this nature approved in Latin America [3].

The most relevant statements of the regulation are [13]:

- Prohibits discarding WEEE together with household waste

- Officially creates the National Executive Committee with representatives of importers, consumers, and government which will establish the quotes, treatment fees, etc.

- New electronics will be covered by the management system once implemented, while historical (EEE generated before the Decree approval) and orphan waste (EEE from a producer or importer that is not in the market anymore) must pay a treatment fee

- The compliance entities (individual or collective) must present their plans for WEEE treatment, which must be approved by the Controller (Ministries of Health and Environment)

- The processors must show compliance to the national regulation such as operation, permit, environmental impact assessment, ad labour safety, in addition to transparency concerning local and international materials trade according to the regulations, including the Basel Convention

- International materials trade may vary according to the development of technologies in the national territory

- Enterprises in Free Trade Zones can also contemplate the use of the system

- In the case of equipment donations, the donor can transfer the hardware but not the responsibility of the waste (treatment fee should be covered by the donor organisation)

The first pilot dismantling exercise allowed determining the basic requirements such as power tools, manual screwdrivers, plyers, and most suitable personal protection equipment such as gloves, safety eyeglasses, and powder masks. For example, it was found that a leather glove in one hand to hold metal carcasses and a bare hand to use the power tool worked best for CPU dismantling. Timing the operations required for the dismantling of a complete computer, as well as other required operations such as moving the daily load of WEEE and separated materials in the facility, cleaning up the working area, etc., adding up to the final labour time per computer. The average time for the dismantling for each component for the three operators is shown in Table 2.

For the total costs estimation, other indirect costs were added such as total warehouse area; packaging items such as sacks, wooden pallets, and shipping boxes $\left(1.7 \mathrm{~m}^{3}\right.$ box); international shipping; sales to local marketing; exportation authorisation and documentation; and final process costs and sales due to metal recovery. 
Table 2. Average time for the dismantling of computer devices [14].

\begin{tabular}{ccccc}
\hline \multirow{2}{*}{ Operator } & \multicolumn{4}{c}{ Time (min) } \\
\cline { 2 - 5 } & CPU & CRT * Monitor & Keyboard & Total \\
\hline 1 & 15.0 & 14.5 & 3.5 & 33.0 \\
2 & 14.0 & 16.9 & 2.5 & 33.4 \\
3 & 13.0 & 14.8 & 2.5 & 30.3 \\
Average & 14.0 & 15.4 & 2.8 & 32.2 \\
\hline
\end{tabular}

* CRT corresponds to Cathode Ray Tube.

Since the first pilot exercise was carried out for a low volume of WEEE and excluded experiences and some costs associated with the public collection campaign and local transportation, a second pilot exercise was developed towards the optimisation of the costs assessment. Table 3 shows the results of the costs assessment of both pilot exercises, where the second shows lower costs per computer due to the higher volume processed (60 tons), the economy scale factor, and an optimisation of the packaging, resulting in a significantly lower volume to be exported, which was the highest cost found. The fee was found to be 10.69 US\$ per computer (about 0.5 US\$ per kilogram). This fee should be considered as a baseline, since volumes, technology, and return values of materials can significantly change [15].

Table 3. Costs assessment for the WEEE processing in both pilot exercises [15].

\begin{tabular}{|c|c|c|c|}
\hline Title & Descriptor & $\begin{array}{l}\text { 1st Pilot Exercise } \\
\text { Costs }(\$)\end{array}$ & $\begin{array}{l}\text { 2nd Pilot Exercise } \\
\text { Costs }(\$)\end{array}$ \\
\hline Warehouse area & $\begin{array}{l}\text { Warehouse renting cost for the } \\
\text { processing facility, including a } \\
30 \% \text { benefit }\end{array}$ & -6.37 & -4.0 \\
\hline Dismantling process & $\begin{array}{l}\text { Labour including local transportation } \\
\text { and forklift moving of the materials } \\
\text { inside the facility }\end{array}$ & -4.30 & -4.30 \\
\hline Packaging & Sacks, shipping boxes & -0.13 & 0.13 \\
\hline Local market & $\begin{array}{l}\text { Sales of copper, aluminium, ferrous } \\
\text { metals, and plastics }\end{array}$ & +0.46 & +0.46 \\
\hline Exportation & $\begin{array}{l}\text { Shipping logistics services, Basel } \\
\text { Convention declaration and permits, } \\
\text { shipping and final processing of CRTs } \\
\text { and PVC *-covered wiring at certified } \\
\text { international processing facilities }\end{array}$ & -7.91 & -3.95 \\
\hline International market & $\begin{array}{l}\text { Sales return for precious metal recovery } \\
\text { in circuits }\end{array}$ & +1.23 & +1.23 \\
\hline TOTAL & & -17.02 & -10.69 \\
\hline
\end{tabular}

Note: negative values represent costs, while positive values represent benefit or return. * Polyvinyl chloride polymer.

Manuals were prepared for equipment disassembly, estimated equipment disassembly times, and working diagrams as a result of the pilot plans and disassembling exercises. The best practices for storage and transportation procedures were evaluated. Packing units were designed and manufactured for testing purposes; however, the high manufacturing cost caused them not to be used in the pilot projects, and a simpler one was prepared. Additionally, information about the possible sites for treating and marketing the separated materials were prepared. 


\section{Limitations of the Process}

- The change of the political party ruling the country and the roles and responsibilities of the state institutions responsible for leading the Decree approval produced a delay of several years, affecting key issues in the strategy implementation.

- It was not possible to motivate municipalities and other related institutions to participate in the two phases in spite of the efforts made.

- There was a lack of knowledge on how to recover, reuse, or recycle materials e.g., Cathode Ray Tubes of monitors.

\section{Conclusions}

- When installing a recovery and recycling system for WEEE, existing collecting, transporting, and recycling enterprises should be incorporated.

- Regulation on WEEE should be based on existing national legislation to reduce approval times.

- The national strategy must be the result of a consensus among the different stakeholders that are participating in the process through private public partnerships.

- The identification of the possible institutions and organisations related to the EEE and their capacity and accountability were fundamental in setting up the National Technical Committee.

- The participation of institutions and individuals of different backgrounds enriched the National Technical Committee with different points of view. Nevertheless, this also implied having to invest major efforts in negotiation processes to be able to reach agreements through consensus. The leading organisation for the constitution of such a committee should be an independent organisation that is neutral to enable interdisciplinary and inter-institutional exchange.

- When WEEE as a subject was placed on the national agenda, it began to generate a demand for the environmentally safe treatment of EEE.

The process developed in Costa Rica has caught the attention of several regional organisations in both Central America and the rest of Latin America, including some governmental institutions and companies.

Acknowledgments: We would like to thank all anonymous reviewers for their inspiring and constructive comments on the paper. Additionally, we gratefully acknowledge the funding provided by the Dutch government through the framework of Bilateral Agreements for the Sustainable Development of Costa Rica and the Netherlands, the Dutch EEE companies that supported the field trip, Ir. Jeroen IJgosse from WASTE, Advisers on Urban Environment and Development, Eindhoven University of Technology in the Netherlands, and the Transference and Transformation Material Centre of the Instituto Tecnologico de Costa Rica for allowing the disassembling exercises in its premises.

Author Contributions: Victoria Rudin-Vega conceived and designed the tools for data collection; Floria Roa-Gutierrez and Victoria Rudin-Vega performed the data collection and its analysis; and Lilliana Abarca-Guerrero wrote the paper with Foria Roa-Gutierrez. Authorship must be limited to those who have contributed substantially to the work reported.

Conflicts of Interest: The authors declare no conflict of interest.

Appendix A. Examples of Instrument for Data Collection

Date:

Questionnaire for importers and distributors of electric and electronic equipment

(Computers, printers, scanners, digital cameras, copying machines, and all the components)

Name of applicant:

\section{General Company Information}

1. Company name

2. Address 
3. Telephone number Fax

4. E-mail

5. Interviewed name

6. Gender
1. ( ) Male
2. ( ) Female

7. Position in the company:

8. Years of work in the company:

9. Education level:
1. ( ) Primary
2. ( ) High School
3. ( ) University
4. ( ) Other

10. Company's activity:
1. ( ) Importer
2. ( ) Distributer
3. ( ) Both

11. Company status:
1. ( ) National
2. ( ) International

12. Does the company have other shops in the country?
1. () No
2. ( ) Yes Where?:

13. Does the company have policies, procedures, norms or regulations related to WEEE Management?

1. ( ) No (Go to question 15)

2. ( ) Yes Which one(s) (Please attach them)

14. Who designs them?

15. Is the company aware of WEEE management companies?

1. ( ) No (Go to question 17)

2. ( ) Yes which one(s)

16. Does the company have any kind of share with the WEEE management company?
1. No ( )
2. Yes ( ) Type of share

\section{Products characteristics}

17. Products imported

\begin{tabular}{|c|c|}
\hline Product & Supplier/City/Country \\
\hline & \\
\hline & \\
\hline
\end{tabular}


18. Who are your most important clients?
1. ( ) Workshops
2. ( ) Commerce
3. ( ) Government
4. ( ) Enterprises
5. ( ) Households
6. ( ) Others Who?

19. Which mass media does the company use for promotions of its products?
1. ( ) TV
2. ( ) Radio
3. ( ) Newspaper
4. ( ) Internet
5. ( ) Others. Which ones?

\section{Products and WEEE management}

20. Does the company receive defective equipment for refurbishing?
1. ( ) No (Go to question 23)
2. ( ) Yes

21. Does the company have refurbishing services?
1. ( ) No (Go to question 23)
2. ( ) Yes

22. Does the company reuse spare parts?
1. ( ) No Why?
2. ( ) Yes Which ones?

23. What does the company do with the obsolete equipment?

24. Does the company generate WEEE?

1. ( ) No (Go to question 28)

2. ( ) Yes. Approximately how much a month?

25. Where does the company send them?
1. ( ) Own warehouse
2. ( ) Disposal site. Which one? Who takes the waste there?
3. ( ) Material refuse facility. Which?
4. ( ) Recycling company. Which one?
5. ( ) Others. Which?

26. Who makes the decisions where the waste goes?

27. Does the company pay for the WEEE transfer to any of those places?
1. ( ) No
2. ( ) Yes How much (monthly) 


\section{Other aspects}

28. Do you know any reason why WEEE should be disposed in a different matter than it is done now?
1. ( ) No
2. ( ) Yes Which?

29. Which measures do you suggest to improve WEEE Management in the company and in the country?

30. Who do you think is responsible for WEEE management?
1. ( ) EEE importers and distributors
2. ( ) EEE assembling companies
3. ( ) Commercial enterprises selling the equipment
4. ( ) Refurbishing workshops
5. ( ) Government
6. ( ) Municipalities
7. ( ) Clients
8. ( ) Others Specify:

31. Do you know which substances are present in EEE?
1. ( ) No
2. ( ) Yes Which?

32. Do you know the health challenges related to the manipulation of EEE?
1. ( ) No
2. ( ) Yes Which?

33. Is the company interested in participating in a National Strategy Design for WEEE and its implementation?

1. ( ) No Why?

2. ( ) Yes

\section{Household}

No.

PRESENTATION: ACEPESA is performing a research with the objective to determine the type of WEEE management at a national level

Date: Name of applicant:

Gender of interviewed:

1. Did /do you have a computer, printer, or scanner not in use?

1. ( ) No (Go to question 3)

2. ( ) Yes

2. What did you (do you) do with the equipment?

1. ( ) You keep it in your house.

2. ( ) You disposed it with the ordinary waste 
3. ( ) You gave/will give it to a person/recycling company Who/which?

4. ( ) You disposed/will dispose it in empty lot, or river basin

5. ( ) You gave it/will give it to store that sells the equipment Which?

6. ( ) Gave it/will give it as donation

7. ( ) Sold/will sell it

8. ( ) Others. Which?

3. Are you willing to pay for a person/enterprise that receives the equipment and manages it in an environmental way?

1. ( ) No (Go to question 5)

2. ( ) Yes

4. How much are you willing to pay to dispose your equipment?

1. ( ) Less than $₫ 1.000$

2. ( ) Between $\phi 1.000$ to less than $₫ 2.000$

3. ( ) Between $₫ 2.000$ to less than $₫ 3.000$

4. ( ) More than $₫ 3.000$

5. Do you have any suggestion for a better WEEE management system?

\section{Appendix B. Tool for Interviews with Waste Pickers at Disposal Sites}

1. Do you recuperate computers, printers, or photocopying machines or spare parts of that equipment?

2. From where does that equipment come?

3. Is the equipment or spare parts mixed with regular waste or does it come separated?

4. Which materials are you recuperating and how do you do it?

5. To whom do you sell it?

6. What price do they pay for it?

7. How did you get information about those buyers?

8. Which conditions do they request for that equipment?

9. Do you know the health impacts caused by contact with that equipment?

10. Which advantages do you find in recuperating the equipment?

11. What do you think is a problem in relation to the recuperation of those materials?

Would you please suggest how those materials could be managed?

\section{References}

1. Tanskanen, P. Management and recycling of electronic waste. Acta Mater. 2013, 61, 1001-1011. [CrossRef]

2. Ongondo, F.O.; Williams, I.D.; Cherrett, T.J. How are WEEE doing? A global review of the management of electrical and electronic wastes. Waste Manag. J. 2011, 31, 714-730. [CrossRef] [PubMed]

3. Silva, U.; Ott, D.; Boeni, H. E-waste recycling in Latin America: Overview, challenges and potential. In Proceedings of the Global Symposium on Recycling Waste Treatment and Clean Technology, Cancun, Mexico, 12-15 October 2008.

4. Borthakur, A. Generation and management of electronic waste in India. An assessment from stakeholders perpective. J. Dev. Soc. 2015, 31, 220-248. [CrossRef]

5. Pathaka, P.; Srivastava, R.R. Assessment of legislation and practices for the sustainable management of waste electrical and electronic equipment in India. Renew. Sustain. Energy Rev. 2017, 78, 220-232. [CrossRef]

6. Arroyo-Araya, H.; Marín-Araya, M.; Rudin-Vega, V. Electronic Waste Management in Costa Rica: Systematization of the Methodology; Bilateral Project-Costa Rica/The Netherlands; Phases I and II, 2003-2007; San Jose, Costa Rica, 2007. 
7. Herrera-Murillo, J.; Rojas-Marín, J.F.; Anchía-Leitón, D. Generation rates and characterization of ordinary solid waste in four municipalities of the metropolitan area Costa Rica. Rev. Geogr. Am. Cent. 2016, 57, 235-260.

8. Programa de Competitividad y Medio Ambiente (CYMA). Reporte Nacional de Manejo de Materiales, Costa Rica. 2006, pp. 66-69. Available online: https://www.ministeriodesalud.go.cr/index.php/ investigacion-y-tecnologia-en-salud/inventarios / inventario-de-tecnologias-en-girs/documentaciontecnica/1387-reporte-materiales-2006/ file (accessed on 20 August 2017).

9. WASTE. Integrated Sustainable Waste Management. Click on ISWM “Approaches". Available online: http:/ / waste.nl/en/our-approach (accessed on 21 December 2017).

10. Guerrero, L.A.; Maas, G.; Hogland, W. Solid waste management challenges for cities in developing countries. Waste Manag. J. 2013, 33, 220-232. [CrossRef] [PubMed]

11. ISSOWAMA (Integrated Sustainable Solid Waste Management in Asia) Consortium. Seventh Framework Programme; European Commission: Brussels, Belgium, 2009.

12. Rudin-Vega, V. Gestión de residuos electrónicos en Costa Rica 2003-2013. Presented at Meeting Platform RELAC, Brasilia, Brasil, 25-27 November 2013.

13. Roa-Gutierrez, F.; Rudin-Vega, V. Costa Rica's first EPR Model towards a sustainable management of e-waste. In Proceedings of the R'07 World Congress Recovery of Materials and Energy for Resource Efficiency, Davos, Switzerland, 1-9 September 2007.

14. Roa-Gutierrez, F.; Salas-Jiménez, J.C. Closing the technological gap on e-waste processing in developing countries: A Costa Rica case study. In Proceedings of the Electronics and Battery Recycling Conference, Canadian Association of Recycling Industries (CARI), Toronto, ON, Canada, 24-26 June 2009.

15. Roa-Gutiérrez, F. Sistema de manejo sostenible para residuos electrónicos. Tecnología Marcha 2009, 22, 3-9.

(C) 2018 by the authors. Licensee MDPI, Basel, Switzerland. This article is an open access article distributed under the terms and conditions of the Creative Commons Attribution (CC BY) license (http:/ / creativecommons.org/licenses/by/4.0/). 